\title{
Exposing the human nude phenotype
}

The recent discovery of the human coun-terpart of the hairlessmousephenotype1has helped our understandingof the molecular genetics of hair growth.But there are no reports of a defect in thehuman homologue of the best known of the 'bald' mouse phenotypes, the nudemouse2.This may be because affected individualsare so gravely ill from the accompanyingimmunodeficiency that their baldness goesunnoticed. We have carried out a geneticanalysis that reveals a human homologue ofthe nudemouse. The nudemouse is characterized by acongenital absence of hair and a severeimmunodeficiency2, resulting from muta-tions in the whn(winged-helix-nude; Hfh11nu) gene, which encodes a member ofthe forkhead/winged-helix transcriptionfactor family with restricted expression inthymus and skin3. The simultaneous occur-rence of severe functional T-cell immunodeficiency, congenital alopecia and nail dys-trophy (MIM database no. 601705) in twoaffected sisters led to the recognition thatthe clinical phenotype was reminiscent ofthe nudemouse4. We therefore investigatedwhether this syndrome represents thehuman counterpart of the nudemousephenotype. We obtained DNA samples from mem-bers of the sisters' family in a small villagein southern Italy. The affected sisters wereborn with a complete absence of scalp hair(Fig. 1a), eyebrows and eyelashes and haddystrophic nails, and no thymic shadow wasevident upon X-ray examination. The firstaffected child revealed a striking impair-ment of T-cell function shortly after birth, and died at the age of 12 months. Her sisterhad similar immunological abnormalities, but bonemarrow transplantation at fivemonths of age led to full immunologicalreconstitution, although the alopecia andnail dystrophy are still present4. We performed linkage analysis usingmicrosatellite markers near the humanWHNlocus on chromosome 17, and founda lod score of 1.32 , suggestive of linkage. Wethen sequenced the human WHNgene5andfound a homozygous C-to-T transition atnucleotide position 792 of the WHNcDNA(GenBank accession no. Y11739) (Fig. 1b).This leads to a nonsense mutation atresidue 255 (R255X) in exon 5, and predictsthe complete absence of functional proteinas a result of nonsense-mediated decay ofmessenger RNA.Because the proband's bonemarrowtransplant was from her brother, we exam-ined her leukocyte DNA both before andafter the graft for the presence of chi-maerism. Genotyping the proband beforethe transplant showed that her leukocyteDNA was homozygous only for the mutantallele (Fig. 1c). Four years after the transplant, we detected the haplotype specific forthe wild-type paternal WHNallele receivedfrom the brother, as well as the mutantallele, indicative of chimaerism. Genderdetermination revealed that the proband'sleukocyte DNA was genotypically XXbefore the transplant, and the brother'sDNA was $X Y$. Afterwards, the proband'sleukocyte DNA was found to be XY (Fig.1c), providing evidence of longtermengraftment and expansion of the bone-marrow graft.The WHNgene encodes a transcriptionfactor, which is developmentally regulatedand directs cell-fate decisions6.In mam-mals, whnis expressed specifically in theepithelial cells of the skin and thymus, where it helps to maintain the balancebetween growth and differentiation7,8.Recent evidence9has highlighted theimportance of the thymic microenviron ment in determining the T-cell repertoire, as both positive and negative selection ofdeveloping T cells depends on cell-cellinteractions with the thymic epithelium. Inwhnknockout mice, the defect has beenlocalized to the differentiating thymicmicroenvironment rather than to a defectin the developing T cells7. The proband wasfree of infections for four years after thebone-marrow transplant, indicating that T-cell function was at least partly restored.This is probably due to mature T cells ofdonor origin, although we cannot excludethe possibility that 
positive selection of Tlymphocytes occurs in the peripherydespite the mutated whngene.Our findings provide evidence of ahuman immunodeficiency caused by a geneexpressed not in haematopoietic cells10, butin specific epithelial cells. In the human hairfollicle, expression of WHNis sharplydemarcated in defined cell populations (Fig.1d). Although nudemice appear to be com-pletely naked, the dermis contains a normalnumber of hair follicles, but they areincompletely developed. The fact that onlyshort, bent hairs occasionally emerge fromthe epidermis is thought to result fromimpaired keratinization11. Together with thehairlessgene1, our finding extends the evi-dence implicating cell-type-specific tran-scription factors in hair-follicle cycling andmorphogenesis, and indicates that baldnessis an extremely complex phenotype.

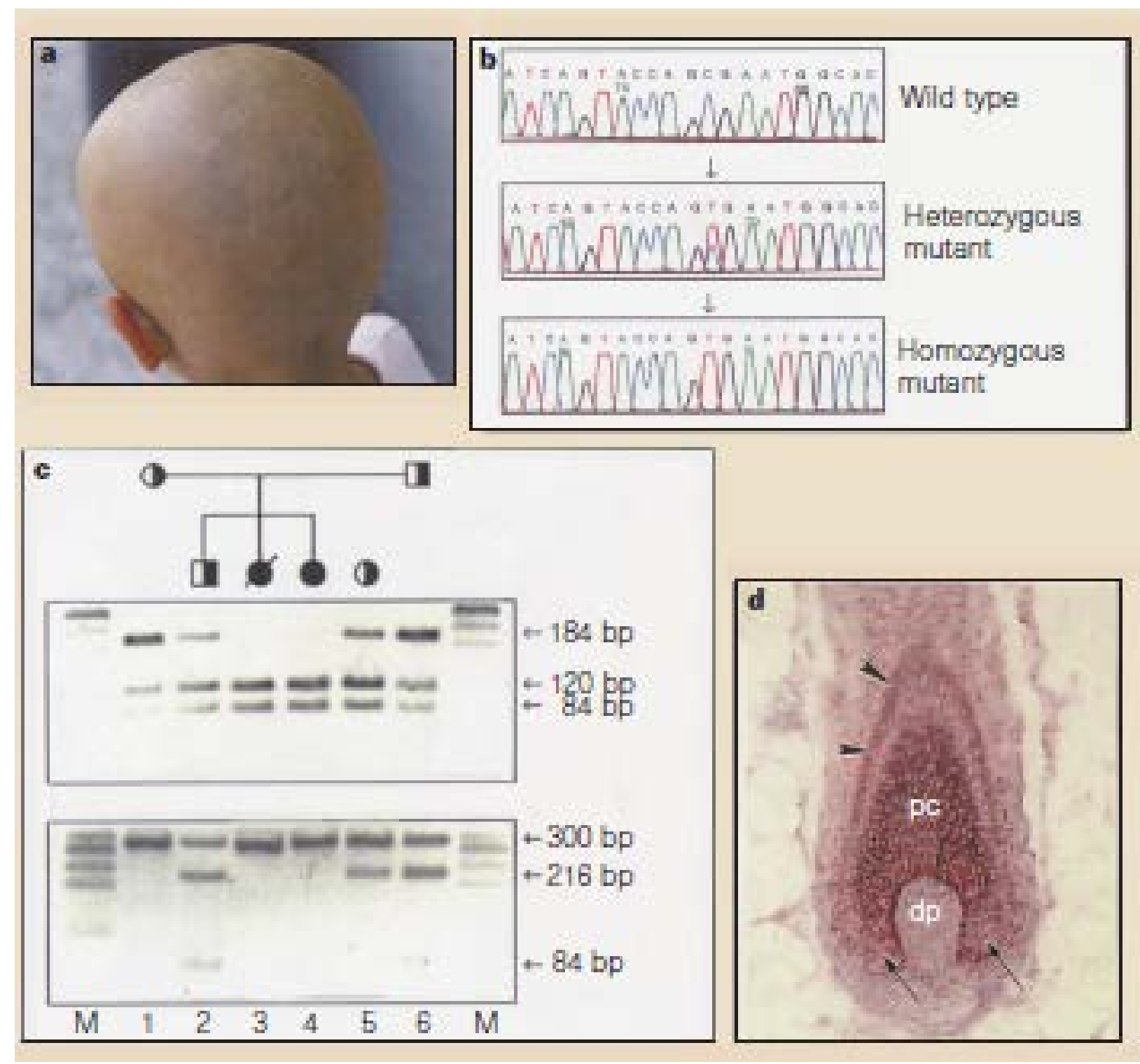

Figure 1. Molecular analysis of the human nudephenotype. a,A five-year-old child with congenital alopeciaand T-cell immunodeficiency. $b$,Sequence analysis of a nonsense mutation in exon 5 of the WHNgene. Top,homozygous wild-type sequence from an unrelated, unaffected control individual. Middle, sequence from aheterozygous carrier of the mutation R255X; arrow indicates a double T\&C peak. Bottom, homozygousmutant R255X sequence from the affected individual; arrow indicates mutant T only, leading to a C-to-T transi-tion (CGA to TGA) and a substitution of an arginine residue 
by a nonsense mutation. c, Restriction-enzymedigestion confirms the mutation. The mutation introduced a restriction site for Bsrl and, after digestion of the184-base-pair (bp) polymerase chain reaction (PCR) product containing exon 5 , the product generated fromthe mutant allele should cleave into two bands of 120 and $64 \mathrm{bp}$. Top, the unaffected parents and brother hadthree bands of 184,120 and $64 \mathrm{bp}$ (lanes 1, 2 and 6), indicating that they were heterozygous carriers of themutation R255X. Both patients had only the two digested bands of 120 and 64 bp (lanes 3 and 4), consistentwith the presence of the mutation in the homozygous state. Bottom, evidence for longterm engraftment ofthe bone-marrow transplant. Gender determination of family members revealed a genotypically XX pattern ofan undigested 300-bp band in the mother (lane 1 ) and affected patients (lanes 3 and 4), and a genotypicallyXY pattern consisting of the 300-bp band and two additional bands of 216 and $84 \mathrm{bp}$, indicative of the $\mathrm{Y}$ chro-mosome, in the brother (lane 2) and father (lane 6). Lane 5, peripheral blood leukocytes from the patient afterthe transplant, demonstrating an $\mathrm{XY}$ genotype and the presence of the normal WHNallele, providing evi-dence for fraternal chimaerism and persistence of the graft. $M$, size markers. d,WHNmRNA expression innormal human scalp skin. In the hair bulb, WHNmRNA is localized to the differentiating cells of the hair follicleprecortex ( $\mathrm{pc}$ ) and the innermost cell layer of the outer root sheath (arrowheads); the dermal papilla (dp)fibroblasts and hair matrix below the level of Auber (small arrows) remain negative for WHNmRNA.

Jorge Frank*, Claudio Pignata†, Andrei A.Panteleyev*, David M. Prowse $\neq$, HowardBaden $\ddagger$, Lorin Weiner $\neq$, Lucia Gaetaniello†,Wasim Ahmad*, Nicola Pozzi†, Peter B.Cserhalmi-Friedman*, Vincent M. Aitaף, Hendrik Uyttendaele*, Derek Gordon§,Jurg Ott§, Janice L. Brissetteł, Angela

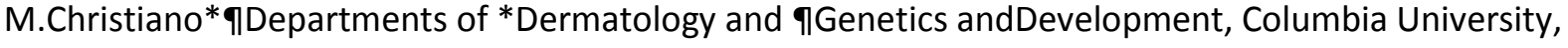
New York, New York 10032, USAe-mail:amc65@columbia.edutDepartment of Pediatrics, Unit of Immunology,Federico II University, Naples, Italy $¥$ Cutaneous Biology Research Center, MassachusettsGeneral Hospital, and Department of Dermatology,Harvard Medical School, Charlestown,Massachusetts 02129, USA§Laboratory of Statistical Genetics, The RockefellerUniversity, New York, New York 10021, USA

References: 1.Ahmad, W.et al.Science279,720-724 (1998).2.Flanagan, S. P. Genet. Res.8,295-309 (1966).3.Nehls, M., Pfeifer, D., Schorpp, M., Hedrich, H. \& Boehm, T.Nature372,103-107 (1994).4.Pignata, C. et al.Am. J. Med. Genet.65,167-170 (1996).5.Schorpp, M., Hoffmann, M., Dear, T. N. \& Boehm, T.Immunogenetics46,509-515 (1997).6.Kaufmann, E. \& Knöchel, W. Mech. Dev.57,3-20 (1996).7.Nehls, M. et al.Science272,886-889 (1996).8.Brissette, J. L., Li, J., Kamimura, J., Lee, D. \& Dotto, G. P. GenesDev.10,2212-2221 (1996).9.Muller-Hermelink, H. K., Wilisch, A., Schultz, A. \& Marx, A.Arch. Histol. Cytol.60,9-28 (1997).10.Fischer, A.et al.Annu. Rev. Immunol.15,93-124 (1997).11.Köpf-Maier, P. et al.Acta Anat.139, 178-190 (1990). 